\title{
Desempenho de cultivares de alface submetidas a diferentes níveis de salinidade da água de irrigação
}

\author{
Francisco de A. de 0 liveira ${ }^{1}$, Maria J. S. de 0 . Carrilho ${ }^{1}$, José F. de Medeiros ${ }^{1}$, \\ Patrício B. Maracajá ${ }^{2} \&$ Mychelle K. T. de O liveira ${ }^{1}$
}

\begin{abstract}
RESU MO
Este trabalho foi desenvolvido em ambiente protegido objetivando avaliar o desempenho de cultivares de alface em condições de salinidade. 0 delineamento utilizado foi inteiramente casualizado, e os tratamentos foram distribuídos em esquema fatorial 5 x 5, com cinco cultivares de alface (M ônica SF31, Grandes Lagos 659, Veneranda, Folha Roxa Q uatro Estações e Stella) e cinco níveis de salinidade de

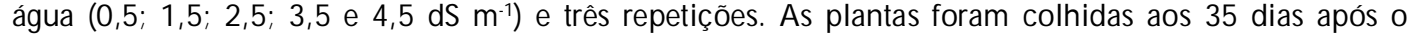
transplantio e avaliados as principais características morfofisiológicas de crescimento: número de folhas, área foliar, comprimento do caule, massa fresca e massa seca das plantas. Verificou-se efeito significativo dos fatores isolados e da interação, para todas as características de crescimento. 0 maior desempenho foi obtido na cultivar Folha Roxa Q uatro Estações. 0 número de folhas, a área foliar e a fitomassa da parte aérea, foram reduzidos linearmente com o aumento da salinidade, sendo os maiores valores obtidos nas cultivares Folha Roxa Q uatro Estações e Stella.
\end{abstract}

Palavras-chave: Lactuca sativa L., estresse salino, recursos hídricos

\section{Performance of lettuce cultivars under different salinity levels of irrigation water}

\begin{abstract}
This study was carried out in greenhouse to evaluate the performance of different cultivars of lettuce under saline conditions. The experimental design was a completely randomized in factorial scheme, with five cultivars of lettuce (M ônica SF31, G randes Lagos 659, Veneranda, Folha Roxa Q uatro Estações e Stella) and five levels of water salinity $\left(0.5,1.5,2.5,3.5\right.$ and $\left.4.5 \mathrm{dS} \mathrm{m}^{-1}\right)$ and three replications. The plants were harvested at 35 days after transplanting and the main morphophysiological growth parameters, that is, the number of leaves, leaf area, stem length, fresh w eight and dry weight of plants were evaluated. Significant effect of the isolated factors and of the interaction for all parameters $w$ as found. The best performance was obtained in cultivar Folha Roxa Q uatro Estações. The number of leaves, leaf area and biomass of shoots were reduced linearly with increasing salinity, with higher values in cultivars Folha Roxa Q uatro Estações and Stella.
\end{abstract}

Key words: Lactuca sativa L., saline stress, water resources

DCAT/U FERSA, BR 110, km 47, CP 137, CEP. 59625-900, Mossoró, RN (84) 3315-1740, E-mail: thikaoamigao@ufersa.edu.br, samara_carrilho@msn.com, jfmedeir@ufersa.edu.br, mkto10@hotmail.com

${ }^{2}$ CCTA/Ū FCG, Campus Ponbal, Rua João Leite, 517, Centro, CEP. 58840-000, Pombal, PB, (83) 3431-2221, E-mail: patrício@ufcg.edu.br 


\section{INTRODUÇÃO}

O setor hortícola possibilita a geração de grande número de empregos devido, sobretudo à elevada exigência de mão-deobra, desde a semeadura até a comercialização. As hortaliças ocuparam, em 2006 uma área de 773,2 mil hectares, produzindo aproximadamente 17,4 milhões de toneladas e gerando quase 3 milhões de empregos no campo (IBGE, 2008).

A alface (Lactuca sativa L.) é uma das hortaliças mais difundidas atualmente, sendo cultivada por todo país, devido, principalmente, a grande divergência genética existente entre as cultivares utilizadas pelos produtores (Sousa et al., 2007), está incluída entre as principais hortaliças de consumo diário e se destaca pelo elevado teor de pró-vitamina A nas folhas verdes, alcançando até 4.000 UI.100g-1 (Filgueira, 2008); sua larga adaptação às condições climáticas adversas, a possibilidade de cultivos sucessivos no mesmo ano, o baixo custo de produção, a pouca susceptibilidade a pragas e doenças e a comercialização segura, fazem com que a alface seja a hortaliça preferida pelos pequenos produtores, o que lhe confere grande importância econômica e social, sendo significativo fator de agregação do homem no campo, destacando-se como a hortaliça folhosa de maior consumo no Brasil (CEASA, 2006).

A disponibilidade mundial de água doce para irrigação está diminuindo em razão da crescente competição com o desenvolvimento urbano e industrial, de forma que o uso de água de qualidade inferior para irrigação se torna um desafio. Para a utilização dessas águas de qualidade inferior na agricultura deve-se utilizar um manejo racional, através de alternativas economicamente viáveis, de modo que a cultura desenvolva a produtividade esperada, boa qualidade dos produtos e com mínimos riscos pelo efeito de salinização dos solos (Medeiros et al., 2007).

A tolerância à salinidade é variável entre espécies e, mesmo em uma espécie, entre estádios de desenvolvimento, em cada fase a tolerância a salinidade é controlada por mais de um gene e altamente influenciada por fatores ambientais (Flowers, 2004; Flowers \& Flowers, 2005; Munns, 2005); entretanto, os efeitos dependem, ainda, de outros fatores, como espécie, cultivar, estádio fenológico, tipo de sais, intensidade e duração do estresse salino, manejo cultural e da irrigação e condições edafoclimáticas (Tester \& Davénport, 2003; Taiz \& Zeiger, 2009; Munns, 2005).

No Nordeste, a maior parte das águas utilizadas na irrigação contém teores relativamente elevados de sais, sendo frequentemente encontrados valores da ordem de 0,1 a 5,0 dS m${ }^{-1}$ (Costa et al., 2004). Segundo Ayers \& Westcot (1999), a alface é "moderadamente sensível" à salinidade, tendo a produção decrescida em $13 \%$ por aumento unitário de condutividade elétrica do extrato de saturação (CEes) acima de $1,3 \mathrm{dS} \mathrm{m}^{-1} \mathrm{em}$ termos de condutividade elétrica de água (CEa) o limiar seria de $0,9 \mathrm{dS} \mathrm{m}^{-1}$, considerando-se a relação entre CEa e CEes, proposta por Ayers \& Westcot (1999) para fração de lixiviação entre 0,15 e 0,20 .

Diante da importância da alface para a região e da necessidade do uso da água de qualidade inferior na irrigação, este trabalho foi desenvolvido objetivando avaliar o desempenho de cultivares de alface irrigada com água de diferentes níveis de salinidade.

\section{Material e MÉTOdos}

O experimento foi conduzido no período de julho a agosto em condições de ambiente protegido, no Departamento de Ciências Vegetais da Universidade Federal Rural do Semi-Árido (UFERSA), município de Mossoró, RN, coordenadas geográficas de $5^{\circ} 11^{\prime} 31^{\prime \prime}$ de latitude sul e $37^{\circ} 20^{\prime} 40^{\prime \prime}$ de longitude oeste de Greenwich, com altitude média de $18 \mathrm{~m}$. O clima da região, na classificação de Köppen, é do tipo BSwh', (quente e seco), com precipitação pluviométrica bastante irregular, média anual de $673,9 \mathrm{~mm}$; temperatura média de $27^{\circ} \mathrm{C}$ e umidade relativa do ar média de 68,9\% (Carmo Filho \& Oliveira, 1995).

A estrutura da casa de vegetação era de aço galvanizado e as paredes laterais e frontais confeccionadas com malha negra com 50\% de sombreamento; a cobertura era em arco tipo túnel, medindo 7,0 m de largura e 18,0 m de comprimento, com manta de polietileno de baixa densidade, transparente, com $0,15 \mathrm{~mm}$ de espessura.

O delineamento experimental utilizado foi o inteiramente casualizado, e os tratamentos foram arranjado em esquema fatorial 5 x 5, com três repetições, sendo a unidade experimental representada por um vaso contendo uma planta. Os tratamentos resultaram da combinação de cinco cultivares de alface (CV1Mônica SF31, CV2-Grandes Lagos 659, CV3-Veneranda, CV4Folha Roxa Quatro Estações e CV5-Stella) com cinco níveis de salinidade da água de irrigação (S1-0,5; S2-1,5; S3-2,5; S4-3,5 e $\mathrm{S} 5-4,5 \mathrm{dS} \mathrm{m}^{-1}$ ). Os diferentes níveis salinos foram obtidos pela dissolução de cloreto de sódio $(\mathrm{NaCl})$ em água proveniente do sistema de abastecimento do campus da UFERSA (S1), cujos valores de condutividade elétrica foram ajustados através de um condutivímetro de bancada com correção para temperatura. As características físico-químicas da água utilizada se encontram na Tabela 1.

Tabela 1. Resultado da análise físico-química da água do sistema de abastecimento utilizada no experimento

\begin{tabular}{lcc}
\hline Parâmetros & Unidades & Resultados \\
$\mathrm{pH}$ & & 8,30 \\
$\mathrm{CE}$ & $\mathrm{dS} \mathrm{m} \mathrm{m}^{-1}$ & 0,50 \\
$\mathrm{Ca}^{2+}$ & $\mathrm{mmol}_{\mathrm{c}} \mathrm{L}^{-1}$ & 3,10 \\
$\mathrm{Mg}^{2+}$ & $\mathrm{mmol}_{\mathrm{c}} \mathrm{L}^{-1}$ & 1,10 \\
$\mathrm{~K}^{+}$ & $\mathrm{mmol}_{\mathrm{c}} \mathrm{L}^{-1}$ & 0,30 \\
$\mathrm{Na}^{+}$ & $\mathrm{mmol}_{\mathrm{c}} \mathrm{L}^{-1}$ & 2,30 \\
$\mathrm{Cl}^{-}$ & $\mathrm{mmol}_{\mathrm{c}} \mathrm{L}^{-1}$ & 1,80 \\
$\mathrm{HCO}_{3}{ }^{-}$ & $\mathrm{mmol}_{\mathrm{c}} \mathrm{L}^{-1}$ & 3,00 \\
$\mathrm{CO}_{3}{ }^{-}$ & $\mathrm{mmol}_{\mathrm{c}} \mathrm{L}^{-1}$ & 0,20 \\
\hline
\end{tabular}

O plantio foi realizado com mudas produzidas em bandejas de poliestireno expandido de 128 células, sendo as sementes semeadas em substrato comercial à base de vermiculita. Quando as mudas apresentaram cerca de 3 a 4 folhas definitivas, foram transplantadas para vasos de concreto, com capacidade para $3 \mathrm{dm}^{3}$. Como substrato utilizou-se uma mistura de material de solo com esterco bovino na proporção 3:1 (v/v). O material de 
solo utilizado neste experimento foi coletado na camada de 0 $20 \mathrm{~cm}$ de um solo classificado como Argissolo Vermelho Amarelo de textura arenosa (EMBRAPA, 1999) coletado em área localizada no Campus da UFERSA.

O material de solo coletado foi peneirado em malha de $2 \mathrm{~mm}$, dele se retirou uma subamostra para caracterização química e física (EMBRAPA, 1997), cujas características são apresentadas na Tabela 2.

Tabela 2. Característicasfísico-químicas do solo utilizado no experimento

\begin{tabular}{lcc}
\hline Parâmetros & Unidades & Resultados \\
$\mathrm{pH}\left(\mathrm{H}_{2} \mathrm{O}\right)$ & & 7,10 \\
$\mathrm{P}$ & $\mathrm{mg} \mathrm{kg}^{-1}$ & 35,61 \\
$\mathrm{~K}^{+}$ & $\mathrm{Cmol}_{\mathrm{c}} \mathrm{dm}^{-3}$ & 0,27 \\
$\mathrm{Ca}^{2+}$ & $\mathrm{Cmol}_{\mathrm{c}} \mathrm{dm}^{-3}$ & 4,10 \\
$\mathrm{Mg}^{2+}$ & $\mathrm{Cmol}_{\mathrm{c}} \mathrm{dm}^{-3}$ & 2,10 \\
$\mathrm{Na}^{+}$ & $\mathrm{Cmol}_{\mathrm{c}} \mathrm{dm}^{-3}$ & 0,11 \\
$\mathrm{H}$ & $\mathrm{Cmol}_{\mathrm{c}} \mathrm{dm}^{-3}$ & 2,48 \\
$\mathrm{Al}^{3+}$ & $\mathrm{Cmol}_{\mathrm{c}} \mathrm{dm}^{-3}$ & 0,05 \\
Densidade do solo & $\mathrm{kg} \mathrm{m}^{3}$ & 1,30 \\
Matéria orgânica & $\mathrm{g} \mathrm{kg}^{-1}$ & 17,00 \\
Areia & $\mathrm{g} \mathrm{kg}^{-1}$ & 900 \\
Silte & $\mathrm{g} \mathrm{kg}^{-1}$ & 20 \\
Argila & $\mathrm{g} \mathrm{kg}^{-1}$ & 80 \\
\hline
\end{tabular}

Nos três primeiros dias após o transplantio das mudas realizou-se a irrigação com água proveniente do sistema de abastecimento do campus da UFERSA, coletada de um poço profundo, cujas características são apresentadas na Tabela 1.

A partir do terceiro dia as plantas foram irrigadas com águas apresentando os diferentes níveis salinos, de acordo com os tratamentos aplicados. A irrigação foi realizada com frequência de uma vez por dia, até 15 dias após transplantio (DAT), quando a irrigação passou a ser realizada com a frequência de duas vezes diárias a partir do $16^{\circ}$ DAT até a colheita, aplicando-se em cada irrigação, um volume de água suficiente para elevar o substrato à capacidade de máxima retenção de água do material de solo. Obteve-se o volume de água de reposição para cada vaso a partir da evapotranspiração real da cultura (ET), sendo caracterizada pela perda de água no conjunto planta-substrato, obtida através de pesagens diárias dos vasos.

A colheita foi realizada aos 35 dias após o transplantio, quando as plantas atingiram o ponto de colheita comercial. As plantas coletadas foram acondicionadas em sacolas plásticas devidamente identificadas e em seguida transportadas para o Laboratório de Irrigação e Salinidade da UFERSA, para serem analisadas quanto as características de crescimento.

As características avaliadas foram: número de folhas (NF), área foliar (AF), comprimento do caule (CC), massa fresca total (MFT) e massa seca total (MST). Para contabilização do número de folhas, utilizaram-se apenas as folhas comerciais. Determinouse a área foliar utilizando-se um integrador de área, modelo LI3100 da Licor, sendo utilizadas todas as folhas de cada planta. $\mathrm{O}$ comprimento do caule foi determinado logo após a separação da parte aérea do sistema radicular, destacando-se as folhas e se realizando, em seguida medições, com o auxílio de uma régua graduada. $\mathrm{O}$ peso da massa fresca das plantas foi determinado logo após a colheita, iniciando-se com o peso da massa fresca total; em seguida, a parte aérea foi separada do sistema radicular e pesada em balança digital de precisão $(0,01 \mathrm{~g})$.

As plantas foram acondicionadas em sacos de papel previamente identificados e postas para secagem em estufa com circulação forçada de ar, na temperatura de $65^{\circ} \mathrm{C}( \pm 1)$, onde permaneceram até atingirem peso constante; em sequencia, as plantas foram pesadas em balança digital de precisão $(0,01 \mathrm{~g})$, e determinada a massa seca da parte aérea (MSPA), massa seca do sistema radicular (MSR) e massa seca total (MST). Os dados obtidos foram submetidos à análise de variância e ajustou equação de regressão entre os vários níveis de salinidade da água (Ferreira, 2000).

\section{RESULTADOS E DISCUSSÃO}

De acordo com a análise da variância, o número de folhas foi afetado significativamente pela salinidade, em que o efeito foi variado para cada cultivar estudada $(\mathrm{p}<0,01)$. Este comportamento demonstra que o efeito do salinidade sobre o crescimento das plantas é variável em função do material genético utilizado, estando assim de acordo com Parida \& Das (2005). Trabalhos desenvolvidos com outras culturas também puderam evidenciar esse comportamento, como observado para o meloeiro (Medeiros et al., 2007), bananeira (Willadino et al., 2011) e feijão caupi (Santos et al., 2009), o que evidencia a importância da seleção de genótipos para cultivo em condições ambientais em que seja inevitável o uso de água salina para irrigação. Independente dos níveis salinos pode-se observar que o maior número de folhas foi constatado nas cultivares CV4 (29 folhas Planta ${ }^{-1}$ ) e CV5 (25 folhas Planta $\left.{ }^{-1}\right)$, enquanto o menor número de folhas foi observado na cultivar CV2 (13 folhas Planta ${ }^{-1}$ ); provavelmente esta diferença se deva às características genéticas de cada cultivar (Figura 1A).

As maiores perdas foram observadas na cultivar CV3 (42,6\%), seguida da cultivar CV4 (39,5\%), enquanto a menor perda foi constatada na cultivar CV2 (26,3\%) (Figura 1A). Para todas as cultivares estudadas, o comportamento das plantas sob condições salinas pode ser explicado por equações lineares, apresentando coeficiente de correlação satisfatório, variando de 0,8457 a 0,9976 (Tabela 3).

Para todas as cultivares estudadas, a salinidade influenciou negativamente a emissão de folhas, e as equações que melhor se ajustaram foram lineares, apresentando coeficiente de determinação satisfatório $\left(R^{2}>0,84\right)$. Verifica-se facilmente que as cultivares estudadas apresentaram comportamentos diferenciados, compondo dois grupos distintos; o primeiro formado pelas cultivares CV4 e CV5, que sempre apresentaram o maior número de folhas emitidas, independente do nível salino aplicado, enquanto o segundo grupo ficou formado pelas cultivares CV1, CV2 e CV3, que mostraram menor número de folhas e não apresentaram diferenças significativas entre si (Figura 1A).

Esses resultados concordam com os encontrados por Viana et al. (2001), que verificaram expressiva redução do número de folhas da alface com aumento da salinidade, mas diferem dos resultados encontrados por Andriolo et al. (2005) que, 
A.
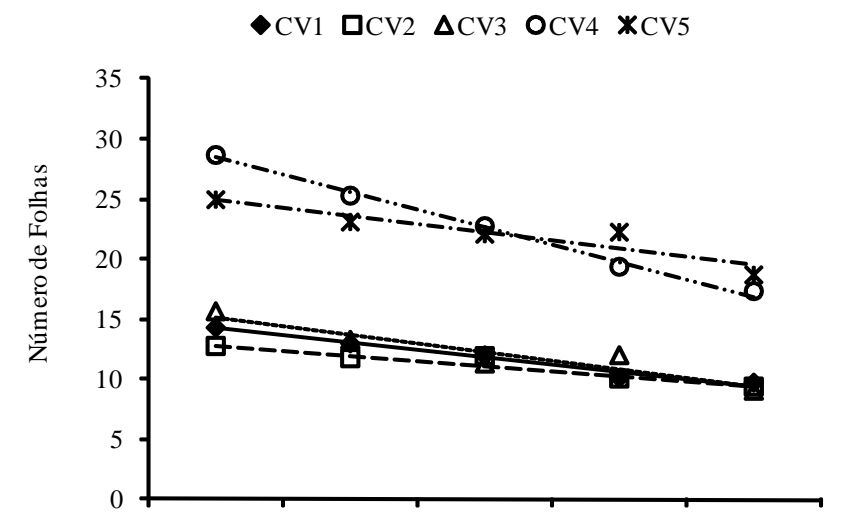

B.

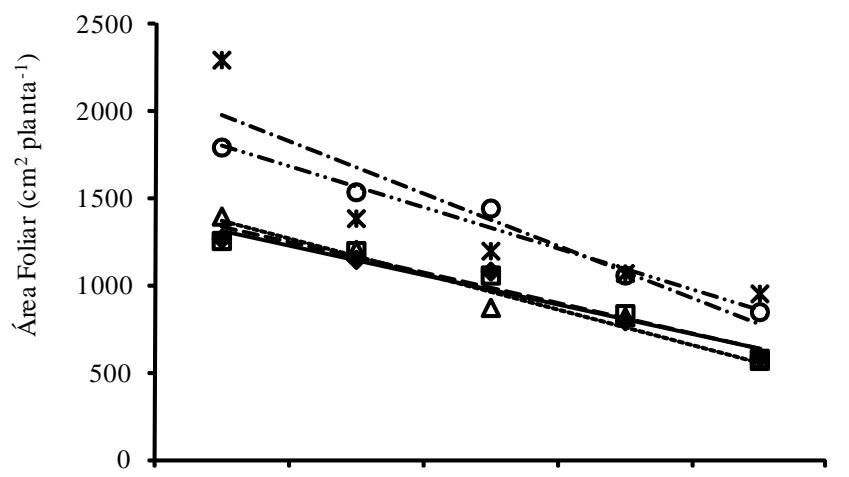

C.

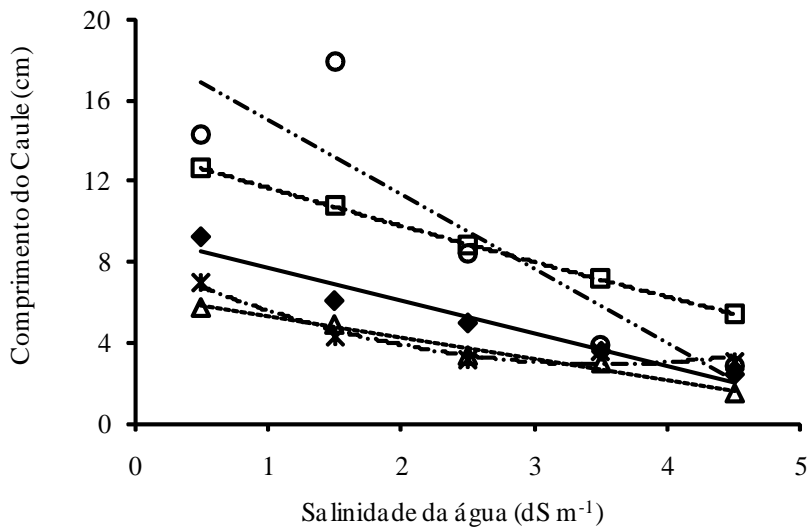

Obs.: CV1-Mônica SF31, CV2-Grandes Lagos 659, CV3-Veneranda, CV4-Folha Roxa Quatro Estações e CV5-Stella

Figura 1. Número de folhas (A), área foliar (B) e comprimento do caule (C) em cultivares de alface produzidas em casa de vegetação e irrigada com água salina

trabalhando com salinidade variando de 0,80 a $4,72 \mathrm{dS} \mathrm{m}^{-1}$, não constataram resposta significativa. Vale salientar que esses autores obtiveram os diferentes níveis salinos a partir de diversas concentrações nutritivas, metodologia incompatível com a utilizada no presente trabalho.

Trabalhos realizados com outras culturas (Oliveira et al., 2006; 2007) também demonstram o efeito da salinidade sobre o número de folhas à medida em que se incrementou a concentração salina da água de irrigação, foram constatados redução no número de folhas nas culturas da mamoneira e milho-pipoca, respectivamente.

A redução do número de folhas em condições de estresse salino é uma das alternativas das plantas para manter a
Tabela 3. Equações de regressão para número de folhas, área foliar, comprimento do caule, massa fresca total e massa seca total de plantas de alface cultivadas em casa de vegetação e irrigada com água salina

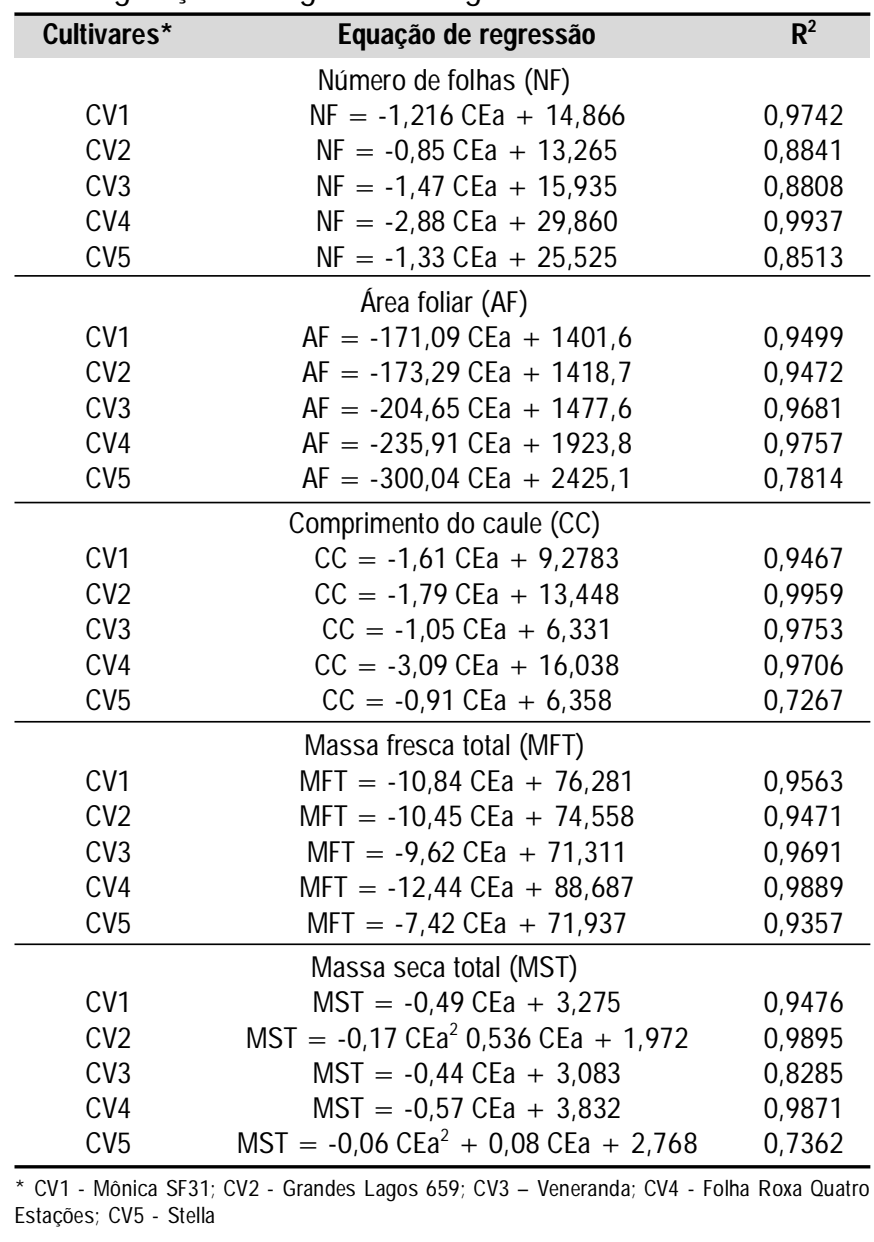

absorção de água, como consequência de alterações morfológicas e anatômicas, refletindo-se na redução da transpiração.

A área foliar apresentou comportamento semelhante ao número de folhas, além de ser afetada significativamente $(\mathrm{p}<$ $0,01)$ pela salinidade em todas as cultivares. Os maiores valores para área foliar foram indicados nas cultivares CV4 (1787,42 $\left.\mathrm{cm}^{2}\right)$ e CV5 $\left(2291,76 \mathrm{~cm}^{2}\right)$, não diferindo entre si estatisticamente, enquanto os menores valores se mantinham na cultivar CV2 $\left(1259,01 \mathrm{~cm}^{2}\right)$, não diferindo estatisticamente das cultivares CV1 e CV3, independente do nível salino, evidenciando que o efeito da salinidade é influenciado pela variação genética entre as cultivares (Figura 1B). Este comportamento permite dividir as cultivares em dois grupos: $\mathrm{o}$ primeiro composto pelas cultivares CV4 e CV5, e o segundo grupo pelas cultivares $\mathrm{CV} 1, \mathrm{CV} 2 \mathrm{e} \mathrm{CV} 3$, resposta semelhante à encontrada para o número de folhas.

Esses resultados demonstram que essas cultivares apresentaram maior adaptabilidade as condições ambientais do local do experimento, evidenciando assim a ocorrência da interação genótipo $\mathrm{x}$ ambiente entre cultivares de alface, conforme relatam Figueiredo et al. (2004).

A equação de regressão que apresentou melhor ajuste foi do tipo linear para todas as cultivares, com coeficiente de 
determinação $\left(\mathrm{R}^{2}\right)$ satisfatório, variando de 0,714 (CV5) a 0,9757 (CV4), de forma que a área foliar foi reduzida com o aumento da salinidade (Tabela 3). Observou-se comportamento bem similar entre as cultivares com redução de área foliar variando de 52,6\% (CV4) a 59,7\% (CV3); no entanto pode-se observar que, mesmo no maior nível salino estudado, as cultivares CV4 e CV5 apresentaram área foliar maior em relação às demais (Figura 1B). Avaliando as Figuras 1Ae 1B, verifica-se comportamentos semelhantes,tanto para número de folhas quanto para área foliar, evidenciando assim que a salinidade afeta tanto a emissão de novas folhas quanto a expansão do limbo foliar (Willadino et al., 2011). Como a principal parte comercial da alface são as folhas, as cultivares CV4 e CV5 apresentam-se como as mais produtivas, provavelmente, em decorrência da maior adaptabilidade as condições de cultivo (Figueiredo et al., 2004).

A área foliar tem sua importância por ser uma variável de crescimento indicativa da produtividade, visto que o processo fotossintético depende da interceptação da energia luminosa e sua conversão em energia química, sendo este um processo que ocorre diretamente na folha (Taiz \& Zeiger, 2009). As folhas constituem um aparato fotossintético e são responsáveis pela formação de carboidratos e estes são alocados para os órgãos vegetativos e reprodutivos das plantas. Como a fotossíntese depende da área foliar, o rendimento da cultura será maior quanto mais rápido a planta atingir o índice de área foliar máximo e quanto mais tempo a área foliar permanecer ativa.

Este menor valor de AF esteve mais relacionado ao tamanho médio de cada folha que ao número de folhas, assemelhandose aos resultados obtidos com maracujazeiro, por Soares et al. (2002). Para alguns autores, redução da área foliar é um importante mecanismo adaptativo de plantas cultivadas sob excesso de sais e estresse hídrico, visto que, sob tais condições, é interessante a redução na transpiração e, consequentemente, diminuição do carregamento de íons de $\mathrm{Na}^{+}$e $\mathrm{Cl}^{-}$no xilema e conservação da água nos tecidos das plantas (Taiz \& Zeiger, 2009). Este decréscimo da área foliar está relacionado a um dos mecanismos de adaptação da planta ao estresse salino, diminuindo a superfície transpirante (Tester \& Davenport, 2003).

Trabalhos desenvolvidos com outras culturas têm evidenciado efeito adverso do estresse salino, provocando redução da área foliar com o incremento do nível salino, como os trabalhos realizados com a cultura do pepino (Folegatti \& Blanco, 2000), e meloeiro (Medeiros et al., 2007), entre outras culturas de importância agronômica.

Os maiores valores para comprimento do caule foram encontrados nas cultivares CV4, CV2 e CV1, com valores de $14,30,12,60$ e $9,23 \mathrm{~cm}$, respectivamente, considerando-se as plantas irrigadas com água de menor nível salino. A salinidade afetou significativamente o comprimento do caule $(\mathrm{p}<0,01)$, o qual foi reduzindo de acordo com o incremento da salinidade. O comprimento do caule foi influenciado pela salinidade de forma diferenciada, de acordo com cada cultivar; no entanto, para todas as cultivares o comprimento do caule foi reduzido com o aumento da salinidade da água utilizada na irrigação. Semelhante às características analisadas anteriormente, as equações de regressão que apresentaram melhor ajuste foram do tipo linear. O comprimento do caule foi a variável mais afetada pela salinidade, com as perdas variando de $56,9 \%$ (CV2) a 79,8\% (CV4).
Avaliando a massa fresca não foi encontrada diferença significativa entre as cultivares no menor nível salino da água da irrigação, com uma produção média de 70,2 $\mathrm{g}$ planta $^{-1}$ para as cinco cultivares, mas com o incremento da salinidade a massa fresca de todas as cultivares foi afetada significativamente pelos níveis salinos da água de irrigação (Figura 2A), demonstrando que a alface é sensível à salinidade; no entanto, este efeito foi variado de acordo com a cultivar avaliada $(\mathrm{p}<$ 0,01). Sabe-se que altas concentrações de sais diminuem o potencial osmótico na solução do solo reduzindo a disponibilidade de água para as plantas, sendo que as culturas mais sensíveis sofrem redução progressiva na produção e componentes de produção sempre que a concentração salina aumenta (Maas \& Hoffman, 1977).
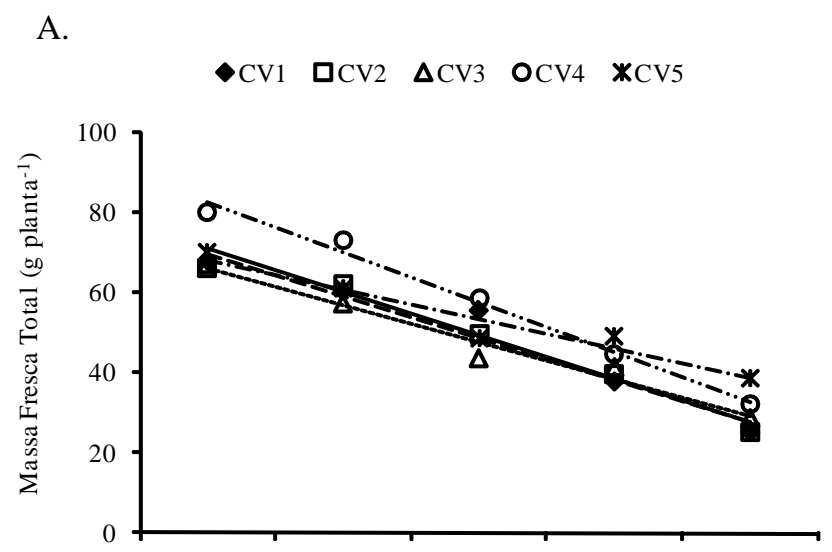

B.

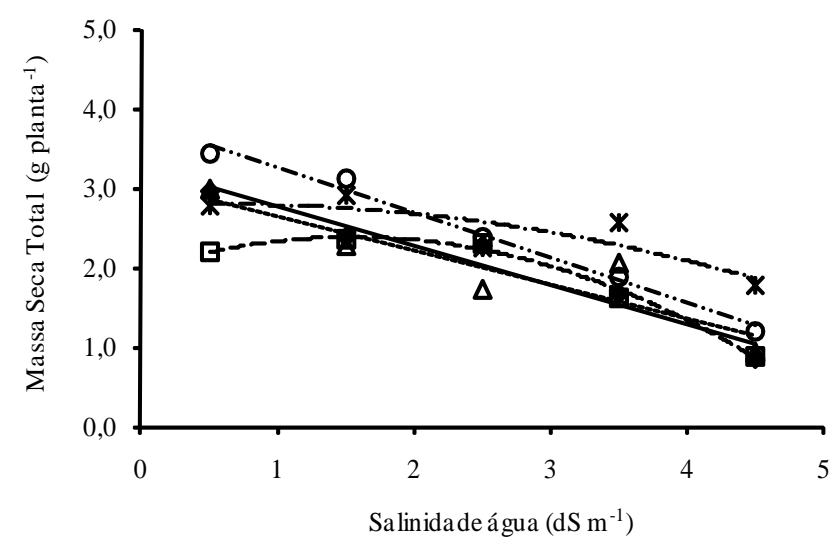

Obs.: CV1-Mônica SF31, CV2-Grandes Lagos 659, CV3-Veneranda, CV4-Folha Roxa Quatro Estações e CV5-Stella

Figura 2. M assa fresca (A) e massa seca (B) de cultivares de al face produzida em casa de vegetação e irrigada com água salina

Para todas as cultivares, o comportamento para o acúmulo de massa fresca pode ser explicado por equações lineares (Tabela 3), ocorrendo redução significativa com o aumento da salinidade da água. As maiores perdas foram encontradas nas cultivares CV1 e CV2, com 72,2\%, enquanto a menor perda foi observada na cultivar CV5, com redução de $38,4 \%$, nas plantas irrigadas com o maior nível salino $\left(4,5 \mathrm{dS} \mathrm{m}^{-1}\right)$ em relação ao menor nível $\left(0,5 \mathrm{dS} \mathrm{m}^{-1}\right)$, resultados que demonstram que a cultivar CV5 apresenta maior tolerância à salinidade (Figura 2A). Paulus et al. (2010) também observaram resposta linear e 
decrescente em duas cultivares de alface, sendo que a redução na massa fresca variou de acordo com cada cultivar.

Viana et al. (2001) também notaram redução linear de fitomassa da parte aérea em decorrência do aumento da salinidade da água utilizada na irrigação para a cultivar de alface 'Elba'; no entanto, Dias et al. (2005) trabalhando com alface, do tipo folhas crespas (Americana) denominada comercialmente Verônica, também em condições de vasos com diferentes níveis de salinidade,constataram resposta quadrática para acúmulo de massa fresca, com maior valor observado na salinidade de $1,0 \mathrm{dS} \mathrm{m}{ }^{-1}$, sendo a massa fresca decrescente a partir deste nível salino.

Para o acúmulo de massa seca não se verificou diferença significativa entre as cultivares quando se utilizou água de menor salinidade $\left(\mathrm{dS} \mathrm{m} \mathrm{m}^{-1}\right)$, com média de 2,9 $\mathrm{g}$ planta $^{-1}$. Semelhante ao acúmulo de massa fresca, a massa seca foi reduzida em todas as cultivares estudadas. As cultivares CV1 e CV2 apresentaram redução sobre a produção de massa seca com o aumento da salinidade; entretanto, só foi observado efeito significativo com salinidade acima de $2,5 \mathrm{dS} \mathrm{m}^{-1}$. Para a cultivar CV4 notou-se o maior efeito da salinidade, com destaque para os maiores níveis salinos, enquanto para a cultivar CV5 não se constatou efeito significativo, apesar de ter ocorrido uma redução de 36\% (Figura 2B). Para as cultivares $\mathrm{CV} 1, \mathrm{CV} 3$ e CV4, as equações de melhor ajuste foram do tipo linear, enquanto para as cultivares CV2 e CV5, foram adotadas equações quadráticas (Tabela 3 ).

Andriolo et al. (2005) avaliaram o desenvolvimento da alface (cv 'Elba') cultivada em areia, aplicando-se diferentes soluções nutritivas com condutividade elétrica variando de 0,80 a 4,72 $\mathrm{dS} \mathrm{m} \mathrm{m}^{-1}$ constataram níveis salinos acima de 2,0 e 2,6 $\mathrm{dS} \mathrm{m}^{-1}$ reduzem o crescimento e a massa fresca das plantas, respectivamente; constataram ainda, que a utilização de água com salinidade de 3,93 $\mathrm{dS} \mathrm{m}^{-1}$ proporcionou redução de 14,27\% na produção da alface crespa.

Sabe-se que a tolerância salina varia com a espécie e, evidentemente, devem ocorrer, também, variações de tolerância salina dentre genótipos da mesma espécie, fato observado neste trabalho. Os efeitos adversos da salinidade no crescimento e desenvolvimento vegetal são complexos e podem resultar de uma combinação de fatores de natureza nutricional, tóxica e osmótica (Ferreira et al., 2007). Vários autores também verificaram redução na massa seca de diferentes culturas em virtude da salinidade do meio, como trabalhos desenvolvidos com milho pipoca (Oliveira et al., 2007) e mamona (Oliveira et al., 2006), entre outras culturas de interesse agronômico.

O excesso de sais na solução do solo modifica as atividades metabólicas das células no processo de alongamento celular, limitando a elasticidade da parede celular, reduzindo o alongamento da célula e, como consequência, o crescimento da planta (Taiz \& Zeiger, 2009). Muitos pesquisadores apontam que um dos principais efeitos da salinidade nas culturas não tolerantes ao sal é a diminuição da taxa fotossintética; este efeito ocorre sobretudo pelo acúmulo excessivo de íons tóxicos, distúrbios na nutrição mineral e/ou redução na turgescência que favorecem a inibição da expansão foliar afetando o processo fotossintético e reduzindo, consequentemente, a produção de fotoassimilados (Munns, 2005).
Os resultados encontrados neste trabalho evidenciam a necessidade do desenvolvimento de pesquisas antes da introdução de determinado padrão genótipo em cada condição ambiental, especialmente em relação à qualidade da água utilizada na irrigação.

\section{ConClusÕES}

1. O número de folhas, a área foliar e a fitomassa da parte aérea foram reduzidos linearmente com o aumento da salinidade, em que os maiores valores foram obtidos nas cultivares Folha Roxa Quatro Estações e Stella.

2. As cultivares apresentaram diferentes respostas para acúmulo de massa seca, com os maiores valores encontrados nas cultivares Folha Roxa Quatro Estações e Stella.

3. A resposta das cultivares Mônica SF31, Veneranda e Folha Roxa Quatro Estações para massa da matéria seca pode ser explicada por regressão linear, enquanto para as cultivares Grandes Lagos e Stella, foram ajustadas equações quadráticas.

\section{LITERATURA CITADA}

Andriolo, J. L.; Luz, G. L.; Witter, M. H.; Godoi, R. S.; Barros, G. T.; Bortolotto, O. C. Growth and yield of lettuce plants under salinity. Horticultura Brasileira, v.23, p.931-934, 2005.

Ayers, R. S.; Westcot, D. W. A qualidade da água na agricultura. 2 ed. Campina Grande: UFPB, 1999. 153p. Estudos FAO: Irrigação e Drenagem, 29 Revisado

Carmo Filho, F.; Oliveira, O. F. Mossoró: Um município do semiárido nordestino, caracterização climática e aspecto florístico. Mossoró: ESAM, 1995. 62p. Coleção Mossoroense, Série B

CEASA - Central de Abastecimento de Campinas. Padronização: alface. http://.ceasacampinas.com.br/padronização_alface.htm. 18Dez. 2006

Costa, D. M. A.; Holanda, J. S.; Filho, O. A. Caracterização de solos quanto a afetação por sais na Bacia do Rio Cabugi Afonso Bezerra, RN. Revista Holos, v.20, p.112-125, 2004.

Dias, N. S.; Duarte, S. N.; Yoshinaga, R. T.; Teles Filho, J. F. Produção de alface sob diferentes níveis de salinidade do solo. Irriga, v.10, p.20-29, 2005.

EMBRAPA - Empresa Brasileira de Pesquisa Agropecuária. Centro Nacional de Pesquisa de Solos. Sistema brasileiro de classificação de solos. Rio de Janeiro: Embrapa Solos, 1999. 412p.

EMBRAPA - Empresa Brasileira de Pesquisa Agropecuária. Manual de Métodos de Análise de Solo. 2.ed. Rio de Janeiro: Embrapa-CNPS, 1997. 212p.

Ferreira, P. V. Estatística experimental aplicada à agronomia. Maceió: UFAL/EDUFAL/FUNDEPES, 2000. 437p.

Ferreira, P. A.; Garcia, G. O.; Neves, J. C. L.; Miranda, G. V.; Santos, D. B. dos. Produção relativa do milho e teores folheares de nitrogênio, fósforo, enxofre e cloro em função da salinidade do solo. Revista Ciência Agronômica, v.38, p.7-16, 2007. 
Figueiredo, E. B.; Malheiros, E. B.; Braz, L. T. Interação genótipos $\mathrm{x}$ ambiente em cultivares de alface na região de Jaboticabal. Horticultura Brasileira, v.22, p.66-71, 2004.

Filgueira, F. A. R. Novo manual de olericultura: Agrotecnologia moderna na produção e comercialização de hortaliças. Viçosa: UFV. 2008. 421p.

Flowers, T. J. Improving crop salt tolerance. Journal of Experimental Botany, v.55, p.307-319, 2004.

Flowers, T. J.; Flowers, S. A. Why does salinity pose such a difficult problem for plant breeders? Agricultural Water Management, v.78, p.15-24, 2005.

Folegatti, M. V.; Blanco, F. F. Desenvolvimento vegetativo do pepino enxertado irrigado com água salina. Scientia Agrícola, v.57, p.451-457, 2000.

IBGE - Instituto Brasileiro de Geografia e Estatística. Situação da produção e área de hortaliças no Brasil. <http:// www.ibge.gov.br>. 16 Fev. 2008.

Maas, E. V.; Hoffman, G. J. Crop salt tolerance - Current assessment. Journal of Irrigation and Drainage Division, v.103, p.115-134, 1977.

Medeiros, J. F. de; Silva, M. C. C.; Sarmento, D. H. A.; Barros, A. D. de. Crescimento do meloeiro cultivado sob diferentes níveis de salinidade, com e sem cobertura do solo. Revista Brasileira de Engenharia Agrícola e Ambiental, v.11, p.248$255,2007$.

Munns, R. Genes and salt tolerance: Bring them together. New Phytologist, v. 143, p.645-663, 2005.

Oliveira, F. de A.; Medeiros, J. F. de; Oliveira, M. K. T. de; Lima, C. J. G. S.; Galvão, D. C. Desenvolvimento inicial do milhopipoca 'Jade' irrigado com água de diferentes níveis de salinidade. Revista Verde de Agroecologia e Desenvolvimento Sustentável, v.2, p.45-52, 2007.
Oliveira, M. K. T. de; Oliveira, F. de A. de; Medeiros, J. F. de; Lima, C. J. G. S.; Guimarães, I. P. Efeito de diferentes teores de esterco bovino e níveis de salinidade no crescimento inicial da mamoneira (Ricinus communis). Revista Verde de Agroecologia e Desenvolvimento Sustentável, v.1.p.68-74, 2006.

Parida, A. K.; Das, A. B. Salt tolerance and salinity effects on plants: A review. Ecotoxicology and Environmental Safety, v.60, p.324-349, 2005.

Paulus, D.; Dourado Neto, D.; Frizzone, J. A.; Soares, T. M. Produção e indicadores fisiológicos de alface sob hidroponia com água salina. Horticultura Brasileira, v.28, p.29-35, 2010.

Santos, P. R.; Ruiz, H. A.; Neves, J. C. L.; Almeida, E. F.; Freire, M. B. G. S.; Freire, F. J. Germinação, vigor e crescimento de cultivares de feijoeiro em soluções salinas. Revista Brasileira de Engenharia Agrícola e Ambiental, v.13, (Suplemento), p.882-889, 2009.

Soares, F. A. L.; Gheyi, H. R.; Viana, S. B. A.; Uyeda, C. A.; Fernandes, P. D. Water salinity and initial development of yellow passion fruit. Scientia Agrícola, v.59, p.491-497, 2002.

Sousa, C. S.; Bonetti, A. M.; Goulart Filho, L. R.; Machado, J. R. A.; Londe, L. N.; Baffi, M. A.; Ramos, R. G.; Vieira, C. U.; Kerr, W. E. Divergência genética entre genótipos de alface por meio de marcadores AFLP. Bragantia, v.66, p.11-16, 2007.

Taiz, L.; Zeiger, E. Plant physiology. 3.ed. Porto Alegre: Artmed, 2009. 719p.

Tester, M., Davenport, R. $\mathrm{Na}^{+}$tolerance and $\mathrm{Na}^{+}$transport in higher plants. Annals of Botany, v.91, p.503-527, 2003.

Viana, S. B. A.; Rodrigues, L. N.; Fernandes, P. D.; Gheyi, H. R. Produção de alface em condições de salinidade a partir de mudas produzidas com e sem estresse salino. Revista Brasileira deEngenharia Agrícola eAmbiental, v.5, p.60-66, 2001.

Willadino, L.; Gomes, E. W. F.; Silva, E. F. F.; Martins, L. S. S.; Câmara, T. R. Efeito do estresse salino em genótipos tetraplóides de bananeira. Revista Brasileira de Engenharia Agrícola e Ambiental, v.15, p.53-59, 2011. 